\title{
A Review of Sanitation Challenges in Ibadan Metropolis, Nigeria
}

\author{
$1 *$ Olanrewaju, S. O. and ${ }^{2}$ Afolabi, M. B. \\ ${ }^{1}$ Department of Urban and Regional Planning, Kebbi State University of Science and Technology, Aliero, Nigeria \\ ${ }^{2}$ Globalclique | Ibugbe and Partners, Lagos, Nigeria \\ *Corresponding Author's Email: olanrewajusamson9@gmail.com: +2347038540456,
}

DOI: $10.36108 /$ laujoces/0202/40(0141)

\begin{abstract}
Increasing population explosion in Nigerian cities has been accompanied with diverse environmental challenges. One of the variants of such challenges is poor sanitation practices which persist despite series of governmental interventions. It is against this background that in this study, various sanitation challenges in Ibadan metropolis were evaluated with a view to proffering recommendations that will aid the achievement of best sanitation practices and a healthy city. In this study, secondary data were utilized and were sourced from environmental based journals and databanks of government agencies. A critical review of the existing situation revealed that population explosion coupled with high illiteracy rate of the inhabitants of Ibadan metropolis affects their waste management and sanitation practices. Also, many sanitation approaches in the city failed because they were not community oriented, hence citizen participation is minimal. A holistic community-based approach of sanitation practice through the involvement of traditional rulers and community-based organizations and sensitization programme using indigenous language is therefore recommended
\end{abstract}

Keywords: Sanitation, Healthy city, Sewage, waste water

\section{Introduction}

The unguarded rate of urbanization especially in developing countries, which is characterized by population increase, has yielded the pumping of her urban centres. The population characterized urbanization is even worsened as there is a tremendously sharp shift of the populace from the rural areas to urban areas. This shift is driven by the comparative advantage of urban areas over rural areas with respect to job opportunities, civic life and advanced societal exposure. In response to this level of excessive migration, these cities thus become centers of population basin in the world. Another recent trend in urbanization pattern is the movement of populace to nearest cities of better value. Hence prime villages are transforming to urban centers, housing different migrants of nearby lower villages. This later scenario has made the definition of urban area as well as urbanization a discus of much confusion that revolves around industrialization, socialization and population increase. If urbanization is the process of transformation of socio demographic characteristics of an urban area, then these emerging cities are better viewed as being urbanized but if industrialization cannot be detached from the term, popularly acclaimed urban areas are far from the realities of being urban. However, central to the two orients is the agreement that population increase is a vital ingredient of urbanization.

With the rate of urbanization, the cities are left with the responsibilities of catering for the basic needs of their society. It is rather unfortunate that the urban sustaining infrastructure provision remains a challenge to cities administrators and as a result existing urban facilities are over dependent on with little or no provision made available for new ones. With population beyond the threshold capacity of urban facilities, city unsustainability reveals themselves in all forms of urban crisis evidenced in crime, congestion, pollution, fringe development and poor sanitation among 
others. Sanitation is a major challenge in urban centres not only because it is most evident, but it serves as a gate to other numerous environmental and health problems. Little wonder, government of different orientations prioritize this issue among several others. Proper sanitation practice and measure can be a tool of economic, social and environmental development as funds used in ameliorating problems accrued to poor sanitation practice can be channeled towards development. Although no research has established the relationship between the size of an urban area and level of sanitation but the capacities of government with reference to expansion of cities in developing societies is a pointer towards this direction.

Ibadan, the primate city of Oyo state, remains one of the oldest cities in Africa and alongside its counterparts like Ile ife, Oyo and Abeokuta is a developmental engines of southwestern Nigeria. In response to the importance of this city, there has been tremendous population shift (especially form neighbouring towns and villages) which has yielded both spatial expansion and economic development. These development although noteworthy has however been accompanied by series of urban environmental problems whose variant is poor sanitation. Sanitation remains a problem in Ibadan metropolis because of the increasing population and activities, thereby increasing both infrastructural demand and waste generation. Although this challenge has attracted numerous governmental and non-governmental attentions, yet it persists and has left one with the following questions. What is the sanitation situation of Ibadan metropolis? What approach has been used to address poor sanitation in Ibadan metropolis? Why has those approaches been unable to eradicate the challenge of sanitation in the metropolis? These questions and many more are the orient of this paper as it inquires into sanitation challenges in Ibadan metropolis.

\section{The Concept of Sanitation}

Discussions and conferences on sanitation both locally and internationally have been on the increase, and as such the subject matter has attracted numerous definitions (WHO, 2014; UNHabitat, 2006; Rochester, 2005; Sanni, 2015). Sanitation according to Environmental Sanitation Policy (2005) is the principle and practice of effecting healthful and hygienic conditions in the environment to promote public health and welfare, improve quality of life and ensure a sustainable environment. Sanitation is however a process which entails waste disposition. It is in this view that the National Sanitation Guidelines (2000) defines environmental sanitation as a process where people demand, develop and sustain a hygienic and healthy environment for themselves, erecting barriers to prevent the transmission of disease. It is a process capable of mitigating the number of microbial contaminations to a relatively safe level. It is a set of actions geared towards improving the quality of the environment and reducing the amount of disease (Mmom, 2003). These set of actions however ranges from management of water, solid waste and industrial waste to include pollution and noise control while the process involves building, use and maintenance of latrines, sewers, drains and also involves learning, behavior change, organization and collective action with other community action. Hence it is not an overstatement to opine that sanitation is the core of urban livability and sustainability. Sanitation is the all-inclusive process of ensuring that a healthy environment is achieved through both programmes and policies aimed at behavioural change and societal regeneration.

Sanitation aims at the promotion of hygienic health through the prevention of human contact with hazards of wastes as well as treatment and proper disposal of sewage waste water (Wikipedia, 2009). Sanitation which has numerous facets has two important types which are peculiar to immediate situations. These are environmental sanitation and household sanitation. Household sanitation involves household food safety and the maintenance of clean living condition which do not promote the spread of disease. Sanni (2015) while quoting Wordnet (2006), referred to environmental sanitation as the control of man's environment which exercise a deleterious effect in his physical 
Volume 4, Issue 1; March, 2020

environment. This implies that environmental sanitation is the deliberate control of man's environmental system in a manner that a balance of the same is maintained. Safe sanitation promotes health; improves the quality of environment and the living standard of the community while inadequate sanitation can lead to outbreak of several transmissible diseases. Good environmental sanitation will generally advance the quality and aesthetics of the environment at large (Adedibu and Okekunle, 1988)

Internationally accepted definition of sanitation was given by UNESCO which referred to the concept as the maintenance of clean, hygienic circumstance that help to avoid disease through service such as waste collection and disposal or recycling (Oke et al, 2013). It is the act of maintaining clean and hygienic conditions that help prevent disease through senders such as garbage collection and waste water disposal (WHO/UNICEF, 2006). Good sanitation includes appropriate health and hygienic awareness and behavior acceptable and affordable as well as on sustainable sanitation services (Oke et al,, 2015). Environmental Sanitation services are in most cases in developing society enshrined within the power of authority hence carried out by the government of the day. This implies that achievement of a particular government can be measured with the level of environmental sanity being maintained by the same.

Sanitation being the degree to which a clean environment is maintained (Oke et al,, 2013) has evident implication in the case of its shortage. The shortage of water which is predominant in developing urban centres has effect on human health and feeding as well as industrialization and commercial development for which it plays primary role. The world council in 2005 declared that 1.1 billion people lack access to safe drinking water, 2.6 billion people lack adequate sanitation and 1.8 million people die every year from diarrhea disease including ninety percent of children under five years. The health status of household has a negative correlation with insanitary human feacal waste. The negative implication of insanitary environmental condition on human has however been reported in Lagos (Adedibu and Okekunle, 1989; Afon, 2006) and Ibadan (Egunjobi, 1989). Diseases associated with human faecal wastes, poor water and personal hygiene accounts for 5.70\% of the total disease burden or eighty four million life lost per year expressed as DALYS (Disability Adjusted Life Waste), besides posing severe environmental health risk on human population, is also capable of inflicting permanent damage on the ecological systems.

The challenge of sanitation which includes inadequate water supply and sanitary facilities (drains, sewers etc.) and piles of uncontrolled garbage (especially along road networks) are found in the environs of homes, neighbourhood and workplace (Anthony, 2013). This makes evidence the gap between proportion of urban population with improved sanitation and proportion with unsafe conveniences (UN- Habitat, 2003). The relationship between socio economic characteristics and sanitation practice of urban residents as well as the sanitation practice of the same with their attitude makes attempts and approaches to curbing of sanitation problems to be beyond the improvement on the provision of inadequate toilet, reduction of poverty level and regular provision of water to all houses to include sufficient awareness and complete public participation (Anthony, 2013).

Today, urban growth rate in west Africa exceeds municipal's capacities to provide adequate housing and other basic services such as water supply, sanitation, waste disposal, communications and transport infrastructure, health service and education and has served as major threat to such environment (Anthony, 2013). In Nigeria, the problem of solid waste management is a major problem for Lagos metropolis and other cities (Ojeshina and Longe, 1996). Poor sanitation costs Nigeria four hundred and fifty five billion naira each year. 70 million Nigerians use unsanitary or shared latrine while 32 million have no latrine at all and defecate in the open. More than 34 million 
people die from water, sanitation and hygiene related disease" In year 2000, about $40 \%$ of the world's population ( 2.4 billion) had adequate sanitation while global sanitation target is to halve this proportion to $20 \%$ of people in 2015 (Postnote, 2000). The world's population is expected to increase from 7.2 billion to 8.1 billion and 9.6 billion in 2025 and 2050 respectively (Wikipedia, 2020) which implies there will be a sanitation requirement for not less than 1 billion and 2.4 billion people in the projected years. This scenario has started to present itself exactly just as World Health Organization had estimated that in the year 2000, 1.1 billion people still lack access to basic sanitation (WHO and UNICEF, 2000) Although inadequate sanitation is not a recent challenge as it is evident in 1980s and 1990s (Postnote, 2000), however the continuous growth in population at the sight of diversified activities has aided the need for pragmatic steps towards good sanitation.

\section{Healthy City Concept}

A healthy city is one that is continually developing those public policies and creating those physical and social environment which enable its people to mutually support each other in carrying out all functions of life and achieving their full potential (Balogun, 2010). Cities are economic engine of the society, they represent the field of meeting for diversified interests and needs as well as potentials, hence to accommodate these diversities and to achieve sustainable development, a healthy city should be maintained. To achieve a healthy city, there must be solid waste management, proper channelization of sewerage and surface run-off water, provision for green areas, water provision, toilet provision amidst others (Balogun, 2010). Any city can be healthy regardless of its health status (WHO, 2015). The maximum exploration of urban centres potential becomes impossible with the level of degrading of the societies as resources which should be processed into the formers developmental programmes and policies are being channeled to cure her environmental nemesis, these and many more are the problem the healthy city stands to forestall.

Healthy city concept aims at the creation of a health supportive environment to achieve a good quality of life, to provide basic sanitation and hygiene needs, to supply to health care (Balogun, 2010). Healthy city philosophy seeks to enhance the holistic wellbeing of people who live and work in cities based on four criteria which are to: exploit political commitment at the highest levels, institutionalize organizational structure to make change; develop a healthy city visionary plan; invest in formal and informal networking cooperation (Awofeso, 2003). It is an all-inclusive initiative that entails the involvement of local people in decision making which requires political commitment and organization cum community development (WHO, 2015). Healthy city has however been criticized to be over dependent on the preventive tendencies of urban health service and the weakness of institutional and human resource shortcomings (Balogun, 2010). It is also viewed to be only effective in industrialized countries because it does not effectively address unhealthy cities but it tends to aggravate health inequality (Awofeso, 2003). The success of a city towards being healthy at the sight of the current trend of democracy depends on the level of acceptability of both politicians and public through their various stakeholders.

Healthy city is achievable in indigenous cities in Nigeria due to the fact that the concept rebrands the traditional sanitation practices where a participatory process of communal sanitation is done. The political class of this era institutionalizes committees through the "Iyalodes" and other societal chiefs to ensure full participation of the communities while the public on the other side having being aware of their role sees such programme as belonging to all. It is unfortunate that this is not so in our urban centre as globalization and urbanization has diffused the element of traditional ingenuity present in cultures. This situation gets worsened as Nigeria is plagued with unsustainable governance which drives the reduction of populace level of trust hence reflecting in their participation and acceptability of city developmental initiatives. It then becomes hard for healthy city which emphasizes equity, participatory governance and solidarity, intersectoral collaboration 
Volume 4, Issue 1; March, 2020

and action to address the determinants of health (Balogun, 2010) to strive. This political unsustainability evident in diverging policies and programmes has been the shortcoming of the actualization of healthy city in most developing countries.Political peculiarities of different societies could have made Balogun, (2010) opined that the advocates of healthy city neglected the varying political systems across the globe while formulating the concept.

\section{Ibadan City and Its Sanitation Challenges}

The city of Ibadan was founded in 1830s as a refugee camp due to the collapse of Old Oyo and Owu Empires and since its formation, it has had various growths. A variant of this is urbanization rate which Falade, (1998) cited by Oke et al, (2013) reported to be beyond 6\%. At pre-independence and post-independence epoch, both the population and the spatial extent of Ibadan have been on the increase. In 1952, the spatial extent of Ibadan was approximately $103.8 \mathrm{~km}^{2}$, it expanded to $136 \mathrm{~km}^{2}$ in 1987 and estimated to be $400 \mathrm{~km}^{2}$ in 2000 (Areola, 1994; Onibokun, 1995 both cited by Laurent, 2003). The National Population Census recorded the population of Ibadan to be 2,550.593 while its average population density was 828 people per $\mathrm{km}^{2}$ (NPC, 2006).

Like other urbanizing centres in developing countries, Ibadan is faced with plethora of sanitation challenges which includes insanitary condition of buildings, absence of sanitary facilities among others. The prime position of the city affords it the ability to drain migrants from neighboring cities which further aids its degeneration. It is very common to see heaps of refuse littering major streets in the city (Oke et al, , 2013). Sanitation provision in Ibadan (Nigeria's second-largest city) is grossly deficient, as in most cities in sub-Saharan Africa.Most people do not have access to a hygienic toilet; large amounts of faecal waste are discharged to the environment without adequate treatment; this is likely to have major impacts on infectious disease burden and quality of life (AFDB. 2008). Areas in the municipal are without toilet and other sanitary facilities. This view was justified by Oke et al, (2013) who reported that areas in Ibadan South East Local Government are characterized with human excreta which are disposed into open gutters, open spaces and along roads. He (Oke et al, 2013) went further to report that from physical observation, sanitation facilities are in poor condition and cannot promote healthy living. Specific indicators recorded by him (Oke et al, ,2013) are kitchen and bathroom which are made of zinc sheets and pollution of underground water. It is unfortunate that student constitute a significant group of the population vulnerable to sanitation problems and health risks in the city (AFDB, 2008)

$50 \%$ of stagnant pools in Ibadan metropolis emits bad odour, $70 \%$ bred mosquitoes, $24 \%$ obstructed the movement of people and $12 \%$ bred worms and other germ breeding pests (PAI Associates, 1983). Less than a quarter of the Ibadan population (22.6\%) has access to potable water supply and only about a third (32.5\%) has access to sanitation facilities (AFDB, 2008).In most low-income settlements, most households do not have toilets, and open defecation on refuse tips and wasteland, or to open drains, is reported to be widespread; in addition, toilets discharging directly to open drains are reported to be common (Oke et al,, 2013).

\section{Managing Sanitation in Ibadan: An Historical Assessment}

This section appraises various sanitation efforts in Ibadan metropolis. It must however be noted that until recently, sanitation policies and programmes are fashioned by Federal government and implemented in different states hence it is more than necessary to carry out this appraisal from the generic viewpoint and filter it down to Ibadan metropolis. The transition of these efforts along administrative lines was considered as it gives a distinction in approaches and orientation. 
Sanitation in the Pre-Colonial Period: Like every other society in the pre-colonial era, sanitation practice in Ibadan had communal and participatory approach. This witnessed the coming together of community members especially on market days for the cleaning of markets and other central locations. Women are mostly saddled with menial responsibilities such as sweeping and clearing of drains among others while men cut grasses among others. Sanitation practice in this period was fun because it was seen as an avenue to improve family tie, settle quarrels and improve friendship. As a result, prime indigenous cities are neat because sanitation was seen as an integral of the trendy culture. This sanitation practice despite its maintenance is not sustainable as it is characterized with the disposal of waste in house or compound backyards (Salau, 1985). The "Akitan" (dumpsites) systems of refuse collection were utilized and defecation was unguardedly done in nearby farms. It is however noteworthy that this system was able to grant indigenous cities their required environmental situation.

Sanitation in the Colonial Period: In the colonial period, Ibadan assumes a strategic position in Southwest, hence colonial administrators' decisions were firstly and effectively implemented in the city. Most sanitation practices in this era followed the suite of British colonies sanitation outlook. This era witnessed the formalization of institutions such as Ministry of Health and Livestock saddled with the responsibility of maintaining sane environment in the colonies (Adebisi, 2000). At the sight of the teaming population, it is almost impossible for the colonial administrators to handle or cope with insanitary situation that is evolving in the urbanizing societies hence development plan and regulations were utilized. This began with the formulation of first development plan in 1946 which had hygiene and sanitation as its focus. Emphasis was placed on refuse disposal and management of refuse liquid and solid wastes in Abattoir, residential areas and streets which came under the supervision of Local government (Ola, 1984 cited by Adebisi, 2000). The maintenance of a safe and sustainable system through institution requires enforcement through specialized agencies hence school of hygiene was established in Ibadan, Kano and Aba for the production of local sanitation inspectors. These sanitation inspectors carry out door to door inspection of cities to ensure that residents conform to various sanitation standards. Still on the quest to achieve a sane environment, Public Health Act, Criminal Code Act (1958) and Noxious Act (1958) were promulgated.

It is unfortunate that despite the efforts to forcefully align and indoctrinate the indigenous society to Britain orientation of sanitation, the deficiencies of the same which indicators include poor waste disposal and excreta ridden city centers among others are still maintained. Although this programme was popular and slightly effective comparatively to existing situation of the cities but it created sociocultural strain beyond the environmental benefit that it stands to offer. Populace acceptability of this programme is minimal hence indigenes see it as punishment.

Sanitation in the Post-Colonial Period: The exit of colonial administration and entrant of selfgovernment brought population relaxation, commitment and renewed interest in development. It allows the prioritization of the country need to which sanitation is central. The various National development plans recognizes the degrading pattern of sane cities at the increase of industrialization and its concomitant rural urban migration hence it made sectoral arrangement to cater for provision and maintenance of public conveniences and refuse disposal, construction and maintenance of drains, establishment, maintenance and regulation of markets, public convenience etc. The new trend in governmental approach to sanitation witnessed the integration of the latter into administrative bloc of urban governance. Waste disposal boards saddled with the responsibilities of providing and maintaining sewerage, drainage and refuse disposal system were established. Also, sanitation enforcement was taken to the grassroot through the establishment of sanitary inspector department in each local government. 
Volume 4, Issue 1; March, 2020

In 1985, the military government initiated a popular and religiously observed environmental sanitation programme. This programme is characterized with autocratic enforcement as populace (either carrying out sanitation or not) are confined in their various residence. This approach however failed to realize that behavioral pattern of individuals (especially adults) cannot be forcefully changed except through continuous sensitization. The programme has in itself turned to ceremony as people uses the time for different meetings bringing to fore the adage that "one can only force a camel to the river, no one can force it to drink water. This was however followed by promulgation of FEPA Decree 88 of 1985.

At the dawn of democracy in 1999, sanitation became residual responsibilities of states hence each state develop curative strategies based on their sociopolitical and economical vantages. The relationship between the government of each states and the federal government determines the extent of synchronization of their policies and initiatives. Oyo State Government has since this new era of democracy developed series of strategies at meeting the unending sanitation challenges in the state. These includes promulgation of Oyo State Environmental Sanitation Law, establishment of Oyo State Water and Sanitation Agency for the provision of clean water in line with UNICEF goals , and the politically driven youth empowerment scheme of Oyo state. The strategies although reflect the regenerating interest of political class in putting an end to sanitation challenges but its diverse, expensive and non-participatory nature has rendered it incapable of putting an end to the problem. Sustainable Ibadan Project which was formulated to help the city adopt a visionary approach to environmental planning and management as well as build necessary institutional and human resource capacity has not been able to achieve its objective.

\section{Factors Responsible for The Ineffectiveness of Past Approaches}

The following factors have been responsible for the ineffectiveness of past approaches in addressing sanitation challenges in Ibadan. These are:

i. Non-participation of the Populace in Policy Formulation and Programmes: the nonparticipatory nature of past approaches has made it shorter in the address of problem. Ibadan city environmental profile prepared in 1994 was expert dominated with little input from the stakeholders (UNEP, 2008). The organization went further to posit that even when people participate, it is done at the level of consultation. These approaches then tend to be alien to the populace thereby raising questions around its integrity and viability.

ii. Low Level of Education: the low level of education of Ibadan residents affects their attitude to both adaptations to sanitation measures. Oke et al,, (2013) while evaluating sanitation practice in Ibadan South East Local Government Area reported that high proportion of illiterates and low education of people in the area impinges on the method and quality of sanitation practice. The correlate between sanitation and education is such that the tendency to maintain neat environment depends on educational value of individual. The more household gets educated and aware of the side effects of unmanaged solid waste, the more they appreciate effective waste management (Oke et al,, 2013).

iii. Political Unwillingness: the unwilling nature of Political office holders in the implementation of sanitation plans has made such plans victims of shelves. Where these plans are even carried out, they tend to be done with no good interest but to achieve political gains hence subjecting it to implementation strain of political god fathers. 
iv. Unsustainable Government: The transitory nature of government has aidednon-implementation and sustainability of sanitation projects and policies. Every government tends to have different (sometimes diverging) ideas towards occurring issues and challenges which results to abandon of existing projects. This gets worse with the advent of democracy (especially opposition government) where the exit of a government marks the end of its policies.

v. Poor Development Control: haphazard and unguarded development encourages poor sanitation. Occupancy density tends to increase with clumsy developments which at the sight of poor sanitary and related facilities cause urban blight.

vi. Absence of Facility Plan: the non-availability of facility plan is a problem to the sustainability of teaming development. Facilities are insufficiently provided and where provided are done with less cognizance to the population thereby affecting their accessibility and effectiveness.

vii. Underfunding: Sanitation agencies are underfunded in the metropolis and this has affected their efficiency in carrying out sanitation practices. The available waste management trucks is not sufficient in handling the volume of waste generated in the metropolis hence excess wastes are left for roadside degradation

\section{Conclusion}

The following conclusions are drawn from the study:

i. Oyo State Government should involve the masses in sanitation programmes and policies. This should include identification of sanitation problem and its effect, opportunity of the metropolis in effective tackling of sanitation challenge, selection of best sanitation approach and the implementation of the same. Traditional rulers and community based organizationsthat are familiar with the characteristics of the metropolis should also be involved as this will encourage grassroot participation.

ii. Sanitation and Hygiene studies should be included in the curriculum of schools in the metropolis. Also, informal methods of educating the populace onvarious environmental sanitation and procedure should be encouraged. This may include the introduction of waste to wealth programme, report sanitation issue in your neighbourhood and be rewarded programmes among others

iii. Government at all levels should be ready to carry out their function as enshrined in the constitution which includes the protection of environment among others. They should be ready to implement project either through funding or the establishment of institution

iv. Development control unit of Oyo State physical planning authority should be effective in the discharge of their duties by not approving developments that will encourage the overspill of population density in the metropolis. The unit should also ensure that developments to be approved make provision for sanitary facilities while existing developments without sanitary facilities should be mandated to make provision for them.

v. Facility plan should be prepared for the metropolis as this will ensureits random distribution. The random distribution of facilities in the metropolis will aid its accessibility and effectiveness 
Volume 4, Issue 1; March, 2020

The cost of poor sanitation is high that cities cannot afford it. Sustainable development will become a mirage if conscious effort is not placed on resultant of poor sanitation on the same. It then becomes the responsibilities of Oyo State Government through its office holders and agencies, nongovernmental organizations and individuals to ensure that sane environment is maintained.

\section{References}

Adedibu A.A and Okekunle A.A, (1989): Environmental Sanitation in Lagos Mainland: Problems and Possible Solutions. International Journal of Environmental Studies Vol 33 pp 99-109

AFDB, (2008): Environmental and Social Management Plan Summary. www.afdb.org/fileadmin, 2008.

Afon A.O, (2006): The Areal Analysis of Solid Waste Generation in Traditional African City: the Example of Ogbomoso Nigeria.

Awofeso N., (2003): Healthy City Approach. Reflection on a framework for Improving Global Health. World Health Organization vol 81(3).

Balogun F. A. (2010): Management of Traditional Markets in Ibadan: A focus on Ojaba and Oje Markets.

Egunjobi Layi (1989): Perception of Urban and Regional Problem: A pilot study of the city of Ibadan, Nigeria. Macmillan Press.

Laurent Fourchard, (2003). Urban Slums Reports: The case of Ibadan, Nigeria Institut Francais de Recherche en Afrique (IFRA), University of Ibadan. PO Box 21540, Oyo State, Nigeria

Mmom P.C. (2003): Willingness of Port Harcourt Residents to Relocate their Residence: Implication for Urban Decongestion. J. Pedagogy Dev. Special Edition pp 78-89

National Sanitation Guidelines (2000): Publication of the Federal Republic of Nigeria

NPC, (2006): Abstract of Statistics. 2006 Publication of Nigeria Population Commission

Ojeshina and Longe (1996): Peoples' perception on Household solid waste management on Ojo Local Government in Nigeria. Iran J Edition. Health. Sa. Eng, 2009. Vol 6, No 3.pp 209216.

Oke M.O., Atinsola M.A and Aina M, (2013): Evaluation of sanitation practices in Ibadan South East L.G.As of Oyo State, Nigeria. Academic Journal of Interdisciplinary studies. Vol 2(5).Pp 79-94

Postnote, (2000): www. Postnote.com/articles on sanitation culled on 5/3/2000 at $12.50 \mathrm{hrs}$

Sanni M. M. (2015): An Examination of Environmental Sanitation and its Health Hazard in the Polytechnic Ibadan AJIS vol 4(1)

UNEP, (2008): The Sustainable Cities Nigeria Programme (1994-2006): Building Platforms For Environmentally Sustainable Urbanisation.SCP Documentation series, volume 7

UN- Habitat, (2003): United Nations Human Settlement Programme: Nairobi Kenya.

WHO and UNICEF, (2000): Global Water Supply and Sanitation assessment 2000 report: UNICEF/WHO, New York.

WHO/UNICEF, (2006): Meeting the MDG Drinking Water and Sanitation Target: The urban and Rural Challenge of the Decade. WHO and UNICEF Pub. pp 41

Wikipedia, (2009) www.wikipedia.com/sanitation classification information. Culled on the $10 / 03 / 2019$ at $02: 10 \mathrm{GMT}$

Wikipedia, (2014): www.wikipedia.com/sanitation classification information. Culled on the 24/06/2014 at 17:30 GMT 